\title{
Sciendo
}

Administration, vol. 68, no. 4 (2020), pp. 5-6

doi: 10.2478/admin-2020-0020

\section{Tribute to Richard Boyle}

\author{
Geert Bouckaert \\ KU Leuven Public Governance Institute, Leuven, Belgium
}

Lansdowne Road in Dublin has three major assets: its rugby stadium, the Institute of Public Administration (IPA) and Richard Boyle, who is a pillar of the IPA.

I met Richard for the first time at an EGPA (European Group for Public Administration) conference. He was a frequent traveller to EGPA meetings, where he made a difference by presenting fascinating papers on Ireland based on research conducted at the IPA.

There is a stereotypical view of Ireland across continental Europe. Ireland is an isle behind another isle, geographically at the edge of Europe. However, Leuven has its great Irish College (since 1610), which became the Irish Institute for European Affairs. Irish monks, at the end of the sixteenth and at the beginning of the seventeenth century, came to continental Europe, and also to Leuven, to develop Irish culture and language, and to reach out.

In his own way, Richard has done the same. He came to continental Europe as an academic, to develop public administration, to reach out to the international community and to make public administration in Ireland, and even Irish public administration, visible and obvious. For that purpose, he was a supreme ambassador of ideas and reform practices developed in Ireland. Through his Irish case studies, and through his comparative research, he was able to move Ireland, from an isle behind an isle, to the core and centre of European comparative public administration research.

From that point of view, the IPA, and Richard's research, increased not only the supply of Irish data for public administration research, but 
also the demand for Irish evidence in comparative research and the sharing of good practices. This became visible within the OECD, but also in major research networks such as the CRIPO COST Action, where Richard represented Ireland on the management committee. In my capacity as chair of this COST Action - CRIPO stands for 'Comparative Research into Current Trends in Public Sector Organizations' - we developed the COBRA database on agencies. It was a privilege to work with Richard as a reliable, professional and gentle colleague with a good sense of (Irish) humour. Richard was heavily involved, with his colleagues at the IPA, in this 'Common Public Organization Data Base for Research and Analysis'.

Richard was also committed to 'evaluation'. He was involved in many reform evaluation studies. Institutionally, he helped to shape the European Evaluation Society as a treasurer.

Let me come back to the third dimension of Lansdowne Road: rugby. Continental Europe is known for its football. It is said that soccer is a gentlemen's sport played by hooligans. It is said that rugby is a hooligan's sport played by gentlemen. I confirm that Richard combines the best of both worlds. The IPA, with Richard's active presence, has been, is and will remain a gentle academic game played by very gentle men and women. To my colleague and friend Richard Boyle, I say, thank you for being such a gentle and grand academic. 